\title{
Association between C282Y and H63D mutations of the HFE gene with hepatocellular carcinoma in European populations: a meta-analysis
}

Fei Jin, Li-Shuai Qu, Xi-Zhong Shen*

\begin{abstract}
Background: Hereditary hemochromatosis $(\mathrm{HH})$ is an autosomal recessive disorder mainly associated with homozygosity for the C282Y and H63D mutations in the hemochromatosis (HFE) gene. The reports about the C282Y and H63D mutations and hepatocellular carninoma (HCC) were controversial. To clarify the relationship between C282Y and H63D mutations and HCC, a meta-analysis including nine studies (1102 HCC cases and 3766 controls, mainly came from European populations) was performed.

Methods: The association was measured using random-effect (RE) or fixed-effect (FE) odds ratios (ORs) combined with 95\% confidence intervals (Cls) according to the studies' heterogeneity.

Results: Meta-analysis of nine studies showed that $Y$ allele of C282Y was associated with HCC risk: RE OR reached 1.50 (95\%Cl: $1.05-2.14, p$ for heterogeneity $=0.02, I^{2}=0.57$ ). Subgroup analysis of seven studies also showed $Y$ allele was associated with HCC risk in healthy populations: RE OR reached 1.61 (95\%Cl: 1.08-2.39, p for heterogeneity $=0.04, I^{2}=0.55$ ). We further did subgroup analysis in alcoholic liver cirrhosis (LC) patients of four studies (224 cases and 380 controls) and found that both the dominant model and Y allele of C282Y were associated with HCC risk (FE OR reached 4.06, 95\%Cl: 2.08-7.92 and 3.41, 95\%Cl: 1.81-6.41, respectively). There was no distinct heterogeneity among the studies $\left(I^{2}=0\right)$. Sensitivity analyses showed the results were robust in the subgroup analysis of alcoholic LC patients.
\end{abstract}

Conclusions: C282Y mutation was associated with HCC in European alcoholic LC patients.

\section{Background}

Hepatocellular carninoma (HCC) is the fifth most common cancer in the world and the third most common cause of cancer mortality [1]. Hereditary hemochromatosis $(\mathrm{HH})$ is an autosomal recessive genetic condition in which excess iron is absorbed by the intestine and deposited throughout the body [2]. If untreated, affected individuals may accumulate excess iron over the many years of their adult life, and this causes progressive tissue damage [3]. It has been reported that $\mathrm{HH}$ may result in many diseases, including liver disease (fibrosis, cirrhosis, and hepatocellular carcinoma). Some studies reported that liver disease was the most common cause of death of patients with $\mathrm{HH}[4,5]$.

\footnotetext{
* Correspondence: shen.xizhong@zs-hospital.sh.cn

Department of Gastroenterology, Zhongshan Hospital, Shanghai Medical College, Fudan University, Shanghai 200032, China
}

In 1996, Feder and colleagues [6] showed that homozygosity for mutation (C282Y, G>A, rs1800562) in the HFE gene was responsible for the majority of cases of typical phenotypic $\mathrm{HH}$. The frequency of the second variant (H63D, C>G, rs1799945) is also increased in $\mathrm{HH}$ patients, but its penetrance is low. From then on, HFE gene has been postulated as a candidate gene of HCC. Some studies [7-16] demonstrated that C282Y or H63D increased the risk of HCC, while some [17-19] gave negative results. Some large scale cohort studies [20,21] also showed that HFE gene mutation penetrance was low and did not increase the likelihood of death from any cause among the $\mathrm{C} 282 \mathrm{Y}$ homozygotes compared with subjects who had no C282Y mutation.

However, the estimates in these cohort studies were conservative in the sense that in the cohort study period, a proportion of $\mathrm{HH}$ patients had received phlebotomy treatment. As a result, the role of $\mathrm{C} 282 \mathrm{Y}$ and 
H63D mutations in HCC occurrence still merits study. To clarify the relationship between HFE C282Y and H63D mutations and HCC, a meta-analysis was performed.

\section{Methods}

\section{Study identification and selection}

Eligible studies were identified by searching the databases of PubMed and ISI Web of Knowledge for relevant reports published before May 2009. The search criteria "c282y OR h63d" and "liver cancer OR hepatocellular carcinoma" were used. We also searched reports and dissection databases published in the Chinese Biomedical database (CBM), China National Knowledge Infrastructure (CNKI), and Wan Fang (Chinese) database to collect articles of case-control studies or cohort studies on associations between HFE mutations and susceptibility to HCC before May 2009. The reference lists of the retrieved articles were also reviewed to identify additional articles missed by the above search.

Studies were selected if (1) there were available data for at least one of the C282Y and H63D two mutations with risk of HCC using a case-control or cohort design; (2) HCC cases were diagnosed by histopathological biopsy or by elevated AFP and distinct iconography changes (CT, MRI, and B ultrasonography); (3) control subjects were free of cancer. Controls could be composed of healthy subjects, chronic liver disease (CLD), including chronic hepatitis $(\mathrm{CH})$ and LC. CLD was either histologically proven or diagnosed based on concordant clinical, biological, and morphological criteria. Review articles and articles that did not provide genotype data were excluded.

\section{Data extraction and synthesis}

The following information was extracted from each study: first author's surname, year of publication, ethnicity of study population, country where study was conducted, and the number of cases and controls for each C282Y and H63D genotype. When specific results were not reported, we used available tabular data to calculate them.

\section{Statistical methods}

To compare the odds ratio (OR) on the same baseline, we used crude OR to conduct the meta-analysis. The effect of association was indicated as crude OR with the corresponding 95\% confidence intervals (CIs). Because of relatively small sample sizes of individual studies and low frequency of variant alleles and the practical clinical value, we performed meta-analysis only in two models: dominant model $(\mathrm{YY}+\mathrm{CY}$ vs. $\mathrm{CC}$ or $\mathrm{DD}+\mathrm{HD}$ vs. $\mathrm{HH})$ and allele contrast ( $\mathrm{Y}$ vs. $\mathrm{C}$ or $\mathrm{D}$ vs. $\mathrm{H}$ ). The pooled $\mathrm{OR}$ was estimated using the FE model (DerSimonian \& Laird) [22]. The heterogeneity between studies was tested using the Q statistic [23]. If $\mathrm{P}<0.10$, the heterogeneity was considered statistically significant, and the RE model was then used. Heterogeneity was also quantified using the $\mathrm{I}^{2}$ metric, which is independent of the number of studies in the meta-analysis $\left(\mathrm{I}^{2}<25 \%=\right.$ no heterogeneity; $\mathrm{I}^{2}=25-50 \%=$ moderate heterogeneity; $\mathrm{I}^{2}>50 \%=$ large or extreme heterogeneity) [24]. The potential small-study bias was tested using the Egger regression test asymmetry [25] and the Begg's test for funnel plot, which is based on Kendall's tau [26]. Sensitivity analysis was performed by omitting one study at a time to assess the influence of individual studies on meta-analysis. The distribution of the genotypes in the control group was tested for Hardy-Weinberg equilibrium using a goodness-of-fit Chi-square test.

All analyses above were conducted using the STATA version 10.0 software (Stata Corp, College Station, Texas). All P-values were two-sided. A p value less than 0.05 was considered statistically significant.

The statistical power was calculated using the PS software [27]. In order to assess the reliability of the positive association, we calculated false positive report probability (FPRP) [28]. An Excel spreadsheet to calculate FPRP is included with the online material http:// jncicancerspectrum.oupjournals.org/jnci/content/vol96/ issue6. If FPRP $<0.20$, we think the association is reliable. Given that the gene mutation was regarded as causal, we used population-attributable risk (PAR) to refer to the proportion of disease risk in a population that can be attributed to the causal effects of the risk allele. PAR can be assessed by using the formula [29].

\section{Results \\ Eligible studies}

By searching data, we found that 15 articles [7-19,30,31] used case-control or cohort design to explore the relationship between HFE mutation and HCC. Six studies $[7,9,13,18,19,30]$ were excluded either because of insufficient numbers of samples or because they did not provide concrete genotype data. Altogether, nine studies [8,10-12,14-17,31] which contained 1102 cases and 3766 controls met the inclusion criteria and were included in the final analysis. Eight studies were published in English and one study was published in Spanish[16]. Five studies $[8,12,14,16,17]$ used peripheral blood leucocytes, two studies used liver tissue [10,31] and two studies used both blood and liver tissue $[11,15]$ to extract genome DNA. All studies used validated methods to genotype the C282Y and or H63D mutation. Seven studies $[7-9,11,12,14,16,17,31]$ used PCR-RFLP, one study [10] used the Taqman method, and one study [15] used PCR combined with 3'minor groove binding group (MGB) probe fluorescent hybridization. Of the nine studies, eight studies (including 958 cases and 2258 controls) 
Table 1 Main characteristics of all studies included in the meta-analysis

\begin{tabular}{|c|c|c|c|c|c|c|c|c|c|c|c|c|c|c|c|c|}
\hline \multirow{3}{*}{ Author } & \multirow{3}{*}{ Year } & \multirow{3}{*}{ Country } & \multirow{3}{*}{ Study design } & \multirow{3}{*}{ Cases/Controls } & \multicolumn{6}{|c|}{$\mathrm{C} 282 \mathrm{Y}$} & \multicolumn{6}{|c|}{ H63D } \\
\hline & & & & & \multicolumn{3}{|c|}{ cases } & \multicolumn{3}{|c|}{ controls } & \multicolumn{3}{|c|}{ cases } & \multicolumn{3}{|c|}{ controls } \\
\hline & & & & & $\mathrm{CC}$ & $\mathrm{CY}$ & YY & $\mathrm{CC}$ & $\mathrm{CY}$ & YY & $\mathrm{HH}$ & HD & DD & $\mathrm{HH}$ & HD & DD \\
\hline Ezzkiouri & 2008 & Maroc & Case-control & $96 / 222$ & 95 & 1 & 0 & 219 & 3 & 0 & 59 & 34 & 3 & 160 & 60 & 2 \\
\hline Nahon & 2008 & France & Cohort & 103/198 & 91 & 12 & 0 & 180 & 18 & 0 & 75 & 28 & 0 & 149 & 49 & 0 \\
\hline Repero & 2007 & Spain & Case-control & 196/181 & 183 & 12 & 1 & 158 & 23 & 0 & 102 & 85 & 9 & 124 & 52 & 5 \\
\hline Willis & 2005 & England & Case-control & $144 / 1508$ & 119 & 17 & 8 & 1331 & 168 & 9 & & & & & & \\
\hline Hellerbrand & 2003 & Germany & Case-control & $137 / 233$ & 120 & 17 & 0 & 223 & 10 & 0 & 108 & 27 & 2 & 177 & 52 & 4 \\
\hline Cauza & 2003 & Austria & Case-control & $162 / 671$ & 139 & 18 & 5 & 603 & 63 & 5 & 128 & 31 & 3 & 529 & 133 & 9 \\
\hline Boige & 2003 & France & Case-control & $133 / 100$ & 126 & 7 & 0 & 93 & 6 & 1 & 92 & 41 & 0 & 59 & 40 & 1 \\
\hline Lauret & 2002 & Spain & Case-control & $77 / 359$ & 65 & 12 & 0 & 337 & 22 & 0 & 52 & 25 & 0 & 234 & 92 & 33 \\
\hline Beckman & 2000 & Sweden & Case-control & $54 / 294$ & 43 & 10 & 1 & 255 & 38 & 1 & 37 & 17 & 0 & 229 & 59 & 6 \\
\hline
\end{tabular}

also explored the relationship between H63D and HCC (Table 1).

All studies were published between 2000 and 2008. In all studies, the cases were histologically confirmed or diagnosed by elevated AFP and distinct iconography changes (CT, MRI, and B ultrasonography). All the controls were free of cancer. The characteristics of the controls varied across studies: five studies $[8,11,12,15,17]$ used CLD patients (four studies used LC patients as controls and one study used $\mathrm{HCV} \mathrm{CH}$ as controls) and seven studies $[8,10-12,14,16,31]$ included healthy population as controls. LC was diagnosed according to clinical and iconography changes. LC was classified as alcoholic $\mathrm{LC}$ and viral LC according to clinical and virology data. $\mathrm{HCV}$ was the main etiology of CLD in five studies and only a small proportion of CLD was caused by HBV. Studies were conducted in different ethnicities, mainly in European populations; eight studies [8,10-12,15-17,31] were conducted in populations of European ethnicity, and one study [14] was conducted in Marco Africans. The Hardy-Weinberg equilibrium (HWE) p values of $\mathrm{C} 282 \mathrm{Y}$ or $\mathrm{H} 63 \mathrm{D}$ genotypes were below 0.05 in the controls of three studies $[8,12,17]$. The disequilibrium might be caused by population stratification or by genotyping errors. The meta-analysis results were then assessed by excluding these studies.

\section{Meta-analysis results \\ C282Y}

The frequency of the C282Y Y allele was 6.17\% (136/ $2204)$ and $5.08 \%(383 / 7352)$ in cases and controls ( $\mathrm{p}=$ $0.046)$, respectively, indicating that the variant allele was more frequent in cases.

At first, we performed the meta-analysis of nine studies including all controls to explore the association of C282Y polymorphism and HCC. Meta-analysis showed that $\mathrm{C} 282 \mathrm{Y}$ polymorphism was associated with $\mathrm{HCC}$ in allele contrast model ( $\mathrm{Y}$ vs. $\mathrm{C}$ ): FE OR reached 1.50 (95\%CI: 1.05-2.14) (Figure 1) (Table 2). There was distinct heterogeneity among studies ( $\mathrm{p}$ for heterogeneity $\left.=0.02, \mathrm{I}^{2}=0.57\right)$. Sensitivity analysis showed that the result was not robust. There was no distinct small-study bias among the studies (Egger's $\mathrm{p}=0.39$ ). The metaanalysis of dominant model showed a non-significant increased risk to HCC: RE OR was 1.43 (95\%CI: 0.98$2.07, \mathrm{p}$ for heterogeneity $\left.=0.02, \mathrm{I}^{2}=0.55\right)$. There was no distinct small-study bias among the studies (Egger's $\mathrm{p}=0.68)$.

Of the nine studies that explored C282Y mutation, seven studies used healthy controls, while five studies used chronic liver disease patients as controls. To clarify whether or not $\mathrm{C} 282 \mathrm{Y}$ increased HCC in subgroups, we performed subgroup analyses between the comparison of (1) HCC and healthy controls of seven studies, (2) HCC and alcoholic LC patients of four studies, (3) HCC and viral LC patients of four studies.

(1) When comparing C282Y polymorphisms between HCC cases and healthy controls of seven studies, allele contrast (Y vs. C) showed association with HCC: RE OR reached 1.61 (95\%CI: 1.08-2.39) (figure 2) (Table 2). There was heterogeneity among studies ( $\mathrm{p}$ for heterogeneity $\left.=0.04, \mathrm{I}^{2}=0.55\right)$. Sensitivity analysis showed that the result was also not robust (figure not shown). There was no small-study bias among the studies (Egger's $\mathrm{p}=0.65$ ).

(2) Four studies used alcoholic LC patients as controls. Four studies included $224 \mathrm{HCC}$ patients with alcoholic LC and 380 alcoholic LC patients without HCC. Metaanalysis provided more distinct association of $\mathrm{C} 282 \mathrm{Y}$ polymorphism with HCC among alcoholic LC patients. FE OR reached 4.06 (95\%CI: 2.08-7.92, p for heterogeneity $=0.77, \mathrm{I}^{2}=0$ ) in the dominant model (Figure 3 ), and 3.41(95\% CI: 1.81-6.41, $\mathrm{p}$ for heterogeneity $=0.47, \mathrm{I}^{2}$ $=0$ ) as allele $\mathrm{Y}$ compared with allele $\mathrm{C}$, respectively (Table 2). Sensitivity analyses of two models both gave robust results. Figure 4 showed the sensitivity analysis of the dominant model. There was no small-study bias (Egger's p: 0.25-0.43). 


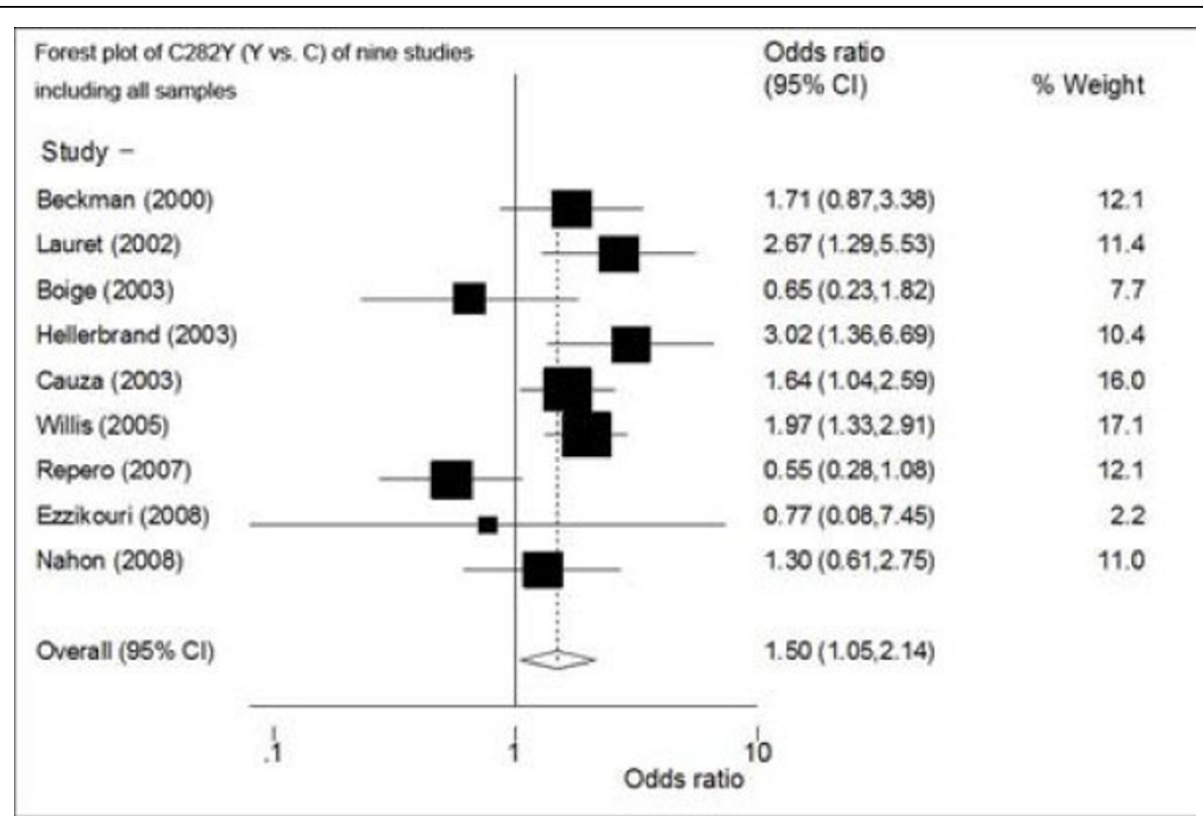

Figure 1 Forest plot of the RE ORs and $95 \%$ Cls of the association between HCC and the C282Y mutation (Y vs. C) of nine studies. The combined estimate is indicated by the diamond. The solid vertical line represents the null result.

(3) Meta-analysis of four studies that used viral LC patients as controls (including 160 case and 203 controls) showed both dominant model and allele contrast had a non-significantly decreased risk of HCC (FE OR $=0.70$, 95\%CI: $0.32-1.50$ and FE OR $=0.71,95 \% \mathrm{CI}: 0.34-1.50$, respectively). There was no small-study bias among studies (Egger's $\mathrm{p}=0.51$ and 0.52 , respectively) and no heterogeneity among studies $\left(\mathrm{I}^{2}=0\right)$ (figure not shown).

H63D

Eight studies (included 958 cases and 2258 controls) provided H63D genotype data. Variant D allele frequency was $16.81 \%(322 / 1916)$ in cases and $14.32 \%$ (657/4516) in controls, respectively.

Overall, this meta-analysis did not show H63D polymorphisms had influence on HCC occurrence. FE OR was 1.19 (95\%CI: $0.90-1.58, \mathrm{p}$ for heterogeneity $=0.01$, $\left.\mathrm{I}^{2}=0.60\right)$ and1.08 (95\%CI: 0.83-1.39, p for heterogeneity $\left.=0.01, \mathrm{I}^{2}=0.61\right)$ in the dominant model and allele contrast model, respectively (figure not shown). There was no small-study bias among studies (Egger's $\mathrm{p}=0.62$ and
0.34 , respectively). We also performed subgroup metaanalysis according to the characteristics of controls (healthy controls and chronic liver diseases controls), but all genetic models did not show evidence of associations with HCC (detailed data not shown).

The statistic power is an important issue on gene-disease association study. As for the association between C282Y polymorphism with HCC among alcoholic LC patients, we used the allele contrast ( $\mathrm{Y}$ vs. C) data to calculate the power. According to the parameters (frequency of the mutation allele $\mathrm{Y}$ in the controls was 0.022 , case number was 224 and control number was 380 , pooled OR was $3.41, \alpha=0.05)$, PS software gave a power of 0.82 , which was satisfactory. However, power of the association study on HCC and viral LC patients (160 cases and 203 controls, frequency of variant allele $\mathrm{Y}=0.05$, pooled $\mathrm{OR}=0.71$, $\alpha=0.05)$ was very low (0.09).

By using the results of the meta-analysis (ORs and $95 \% \mathrm{CIs}$ ) and the knowledge of the epidemiological data of HCC (prior probability) in different populations, we

Table 2 Meta-analysis results of C282Y polymorphism and HCC

\begin{tabular}{|c|c|c|c|c|c|c|c|c|c|}
\hline \multirow[b]{2}{*}{ Genetic model } & \multicolumn{3}{|c|}{ Nine studies of all samples } & \multicolumn{2}{|c|}{$\begin{array}{l}\text { Seven studies of healthy } \\
\text { controls }\end{array}$} & \multicolumn{2}{|c|}{$\begin{array}{l}\text { Four studies of alcoholic } \\
\text { LC }\end{array}$} & \multicolumn{2}{|c|}{ Four studies of viral LC } \\
\hline & Dominant & Allele contrast & CY vs. CC & Dominant & Allele contrast & Dominant & Allele contrast & Dominant & Allele contrast \\
\hline OR & 1.43 & 1.50 & 1.31 & 1.46 & 1.61 & 4.06 & 3.41 & 0.70 & 0.71 \\
\hline $95 \% \mathrm{Cl}$ & $0.98-2.07$ & $1.05-2.14$ & 0.89-1.95 & $0.96-2.22$ & $1.08-2.39$ & $2.08-7.92$ & $1.81-6.41$ & $0.32-1.50$ & $0.34-1.50$ \\
\hline$p$ for hetero & 0.02 & 0.02 & 0.02 & 0.04 & 0.04 & 0.77 & 0.47 & 0.47 & 0.49 \\
\hline $1^{2}$ & 0.55 & 0.57 & 0.56 & 0.54 & 0.55 & 0 & 0 & 0 & 0 \\
\hline Egger's $p$ & 0.31 & 0.39 & 0.99 & 0.97 & 0.65 & 0.25 & 0.43 & 0.51 & 0.52 \\
\hline
\end{tabular}




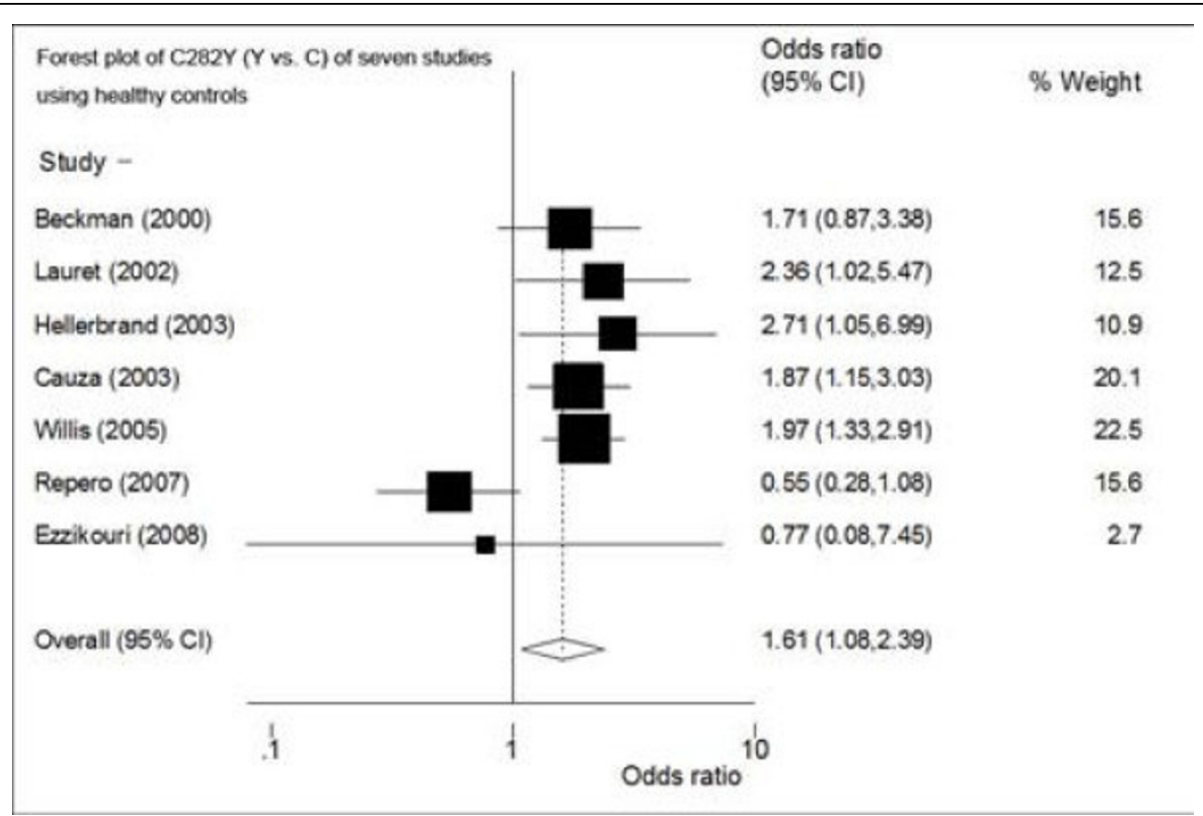

Figure 2 Forest plot of the RE ORs and 95\% Cls of the studies on the association between HCC and the HFE C282Y mutation (Y vs. C) of seven studies (using healthy controls).

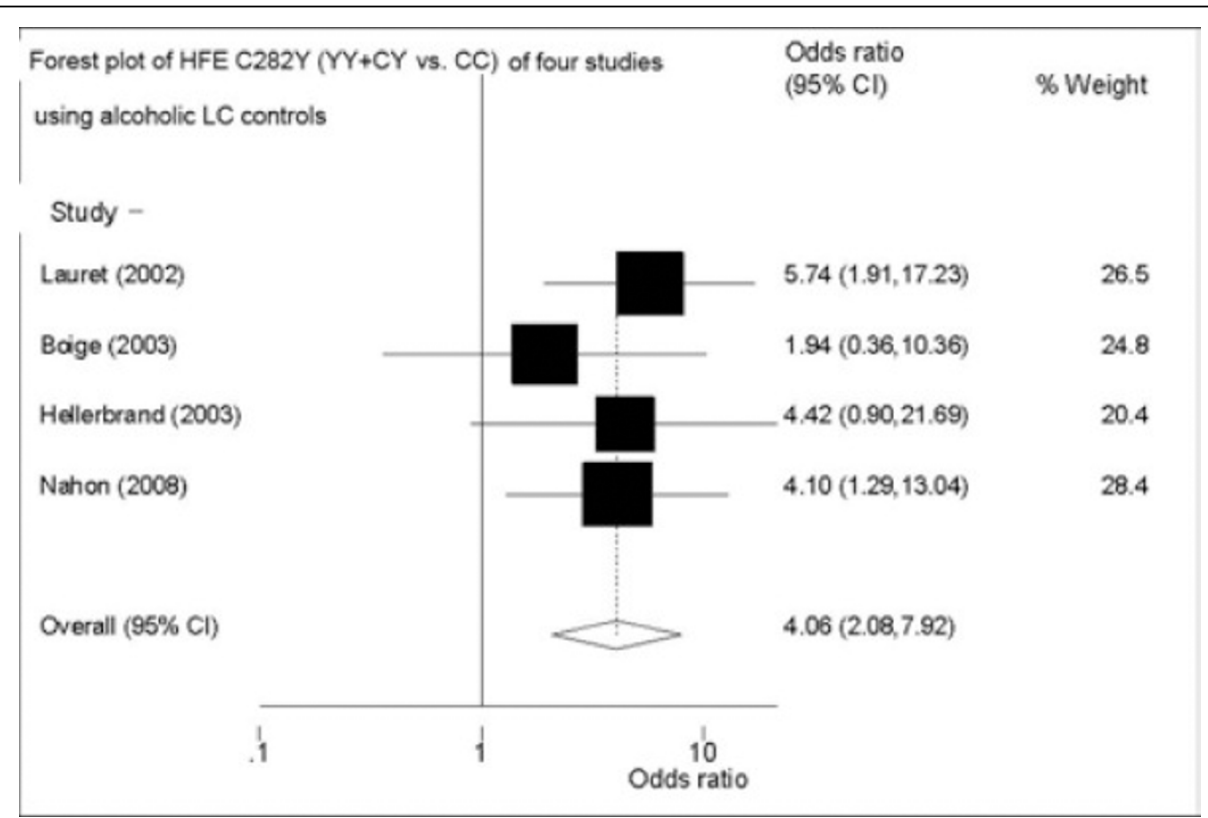

Figure 3 Forest plot of the FE ORs and $95 \%$ Cls of the studies on the association between HCC and the HFE C282Y mutation (YY+CY Vs. CC) of four studies (using alcoholic LC controls).

derived FPRP to assess the reliability of the association. OR of allele contrast ( $\mathrm{Y}$ vs. C) equaled $3.41(95 \% \mathrm{CI}$ : 1.81-6.41) in the subgroup analysis of four studies using alcoholic LC controls. If the prior probability of developing HCC in alcoholic LC patients is assigned at 0.01 , then FPRP was $0.03(<0.20)$.
Given that mutation allele $\mathrm{Y}$ of $\mathrm{C} 282 \mathrm{Y}$ is a risk factor of HCC, we further calculated PAR and its' $95 \% \mathrm{CI}$ in all populations and in alcoholic LC patients. According to the formula from Bruzzi, PAR of allele $\mathrm{Y}$ is $2.48 \%(95 \%$ CI: $1.30 \%-3.65 \%)$ and $5.12 \%(2.57 \%-7.67 \%)$ in all populations and in alcoholic LC patients, respectively. 


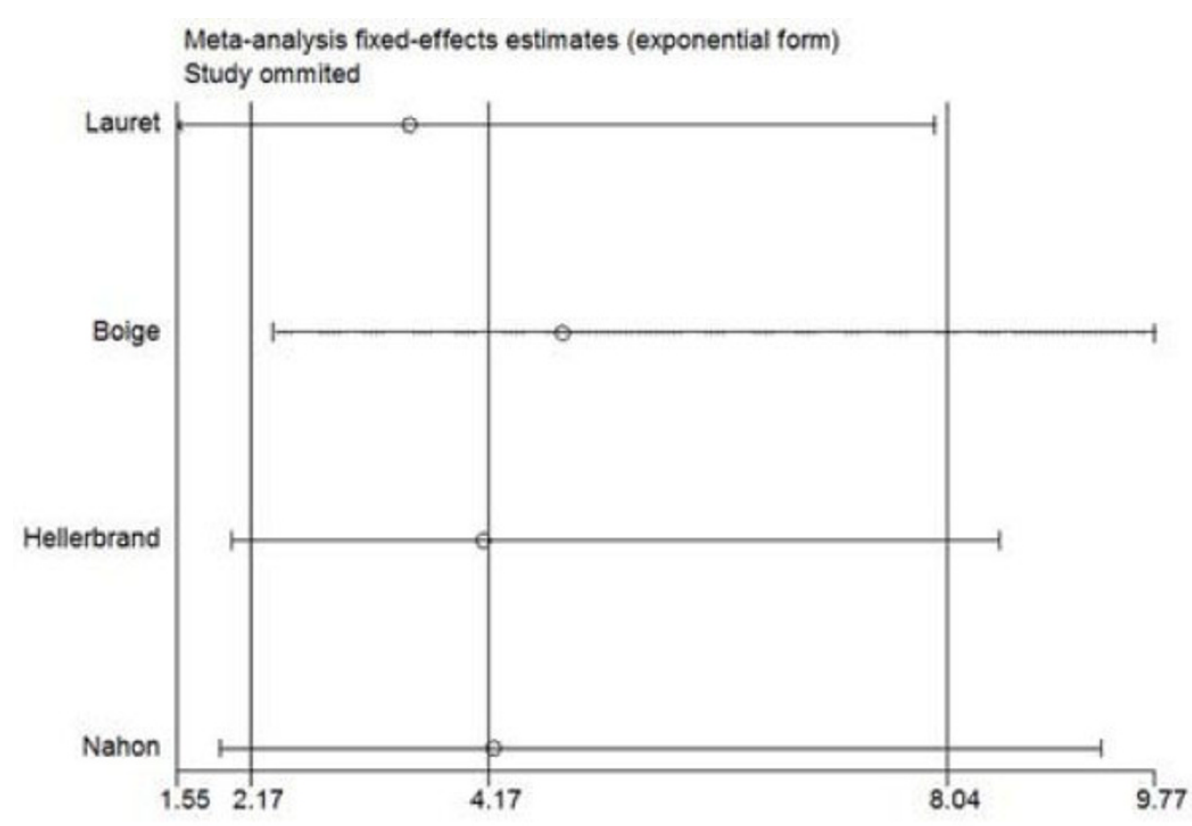

Figure 4 Sensitivity analysis of the association of C282Y (YY+CY vs. CC) and HCC among alcoholic LC patients of four studies, in which the meta-analysis estimates were computed omitting one study at a time. The results indicated the association was robust.

\section{Discussion}

$\mathrm{HH}$ is a common genetic disease in European populations that causes an inappropriately high absorption of iron, leading to the progressive accumulation of iron in the liver. The two missense mutations C282Y of the HFE gene explain most of the cases of $\mathrm{HH}$, a condition characterized by hepatic iron overload. Liver iron accumulation leads to reactive oxygen species formation in the liver, thus causing oxidative stress. It has been shown that the wild-type HFE protein forms a stable complex with the transferrin (TF) receptor (TFR), thereby reducing its affinity for TF [32], whereas the HFE 282Tyr mutation almost completely prevents the formation of a complex between the mutant HFE protein and the TFR, allowing a high-affinity TF binding to the TFR. This binding results in an increased cellular uptake of iron. A second missense mutation in the HFE gene, $\mathrm{H} 63 \mathrm{D}$, is found in about $4 \%$ of patients with $\mathrm{HH}$, but its role in iron overload is still debated [6].

It has been reported that $\mathrm{HCC}$ occurred more in $\mathrm{HH}$ patients than in normal populations in some cohort studies $[4,33,34]$. However, there are also opposite reports that $\mathrm{HH}$ had low penetrance and did not increase the risk of HCC $[20,35,36]$.

From the late 1990s, many researchers have explored the relationship between these two mutations and HCC susceptibility by using case-control or cohort studies [7-9,11-19,30]. In 2007, Christina Ellervik and her colleagues [37] performed a meta-analysis to examine associations between $\mathrm{C} 282 \mathrm{Y}$ and H63D mutations with
HCC. The meta-analysis included nine studies and reported that $\mathrm{C} 282 \mathrm{Y}$ homozygotes $\mathrm{YY}$ versus CC obtained an odds ratio of 11 to HCC occurrence. However, the sample sizes of many studies included in that meta-analysis were too small, leading to low statistical power. From then on, several articles about HFE mutations and HCC have been published. We selected nine eligible studies including 1102 cases and 3766 controls to conduct an updated meta-analysis.

Because $\mathrm{HH}$ is more frequent in northern European populations, the studies on HFE gene mutations and HCC are mainly come from European ethnicities. In this meta-analysis, eight studies were come from Europe and one from Africa. So, the analysis results may be mainly applicable to European populations and it warrants to be studied in other ethnicities. In this meta-analysis, the frequency of C282Y YY homozygotes was $0.42 \%(16 / 3766)$, and the frequency of CY heterozygotes was $9.32 \%(351 / 3766)$ in all control subjects. The genotype distribution was consistent with the dbSNP data. H63D genotype distribution was 2.66\% (60/2258) and $23.78 \%$ (537/2258) for DD homozygotes and HD heterozygotes in controls, respectively.

As to C282Y, the ORs of allele contrast ( $\mathrm{Y}$ vs. C) in the six studies $[8,10-12,15,31]$ were larger than 1.0. Among the six studies, four studies [8,10-12] reported a significant association between $\mathrm{HCC}$ and the $\mathrm{C} 282 \mathrm{Y}$ polymorphism (ORs $>1.0,95 \%$ CIs did not include 1.0). Because the frequency of the homozygous mutation of $\mathrm{C} 282 \mathrm{Y}$ is very low, and a large proportion of $\mathrm{C} 282 \mathrm{Y}$ 
homozygotes had been diagnosed with $\mathrm{HH}$ and received treatment, such as venesection before developing $L C$ or $\mathrm{HCC}$, the conclusion that YY homozygotes increased HCC risk may have little clinical value. Thus, we only explored the dominant model and allele contrast in this meta-analysis. This meta-analysis proved that C282Y mutation was associated with HCC in European populations, especially in alcoholic LC patients but not in viral LC patients. This result is consistent with the results of three previous studies $[8,15,38]$, and it may implicate that the hepatocarcinogenesis of alcoholic LC and viral LC is different and warrants further study. Some studies explored the role of gender in the influence of the relationship between HFE gene and HCC $[10,14,34]$ and found that $\mathrm{C} 282 \mathrm{Y}$ homozygotes YY mutation increased the risk of HCC in male patients. One English study [10] reported that male $\mathrm{C} 282 \mathrm{Y}$ homozygotes were more likely to be diagnosed with $\mathrm{HCC}(\mathrm{OR}=14,95 \% \mathrm{CI}$ : 5 37 ), and the penetrance of the $\mathrm{C} 282 \mathrm{Y}$ homozygous genotype, with respect to $\mathrm{HCC}$, was between $1.31 \%$ and $2.1 \%$ for males and zero for females. Another study [36] reported that $\mathrm{C} 282 \mathrm{Y}$ homozygote males had a relative risk (RR) of about 23 for HCC occurrence, and the penetrance, with respect to HCC, was $5.56 \%$. As there were few studies that provided concrete gender subgroup genotype values, we could not make a pooled analysis.

From the pooled genotype data, we could assess the statistical power under various subgroup analyses using PS software [27]. We noted that the power was satisfactory except when comparisons were performed between HCC cases and viral LC patients (power $=0.09$ ). This indicated that the null association of $\mathrm{C} 282 \mathrm{Y}$ and $\mathrm{HCC}$ when compared in HCC cases and viral LC cases should be taken with caution and that it warranted further study in a larger scale. FPRP is a valuable criterion to assess whether or not a positive discovery came about by chance. We used FPRP to assess the positive association attained by this meta-analysis. The association between C282Y (Y vs. C) and HCC attained by subgroup analysis of four studies using alcoholic LC patients as controls was proved to be reliable (FPRP $=0.03$ ).

Population-attributable risk (PAR) is a valuable parameter to assess the influence of risk factors on disease occurrence. The PAR of the variant allele Y of C282Y among alcoholic LC patients was 5.12\% (95\%CI: 2.57\%$7.67 \%$ ). This result suggested that the role of $\mathrm{C} 282 \mathrm{Y}$ polymorphism on HCC occurrence was modest.

\section{Conclusions}

This meta-analysis proved that $\mathrm{C} 282 \mathrm{Y}$ mutation was associated with HCC in European alcoholic LC patients. The role of $\mathrm{C} 282 \mathrm{Y}$ polymorphism on $\mathrm{HCC}$ occurrence was modest. The association of this polymorphism and
HCC is warranted further studies in large scale including diverse ethnicities. The molecular mechanism of the different effect of C282Y on alcoholic LC and viral LC, with respect to HCC occurrence, also merits further studies. This meta-analysis did not find association of H63D mutation with HCC.

\section{Acknowledgements}

The present study was supported by the China Ministry of Health (2009ZX10004-301), National Natural Science Foundation (No. 30772505, No. 30872503 \& No. 40830744), National Basic Research Program of China (2007CB936004) and China National Key Projects for Infectious Diseases (2008ZX10002-017).

\section{Authors' contributions}

FJ participated in the design of the study and performed the statistical analysis. XZS conceived the study, participated in its design and coordination work, and helped draft the manuscript. LSQ helped search articles and revised the draft. All authors read and approved the final manuscript.

\section{Competing interests}

The authors declare that they have no competing interests.

Received: 25 December 2009 Accepted: 2 March 2010

Published: 2 March 2010

\section{References}

1. Mazzaferro V, Llovet JM, Miceli R, Bhoori S, Schiavo M, Mariani L, Camerini T, Roayaie S, Schwartz ME, Grazi GL, Adam R, Neuhaus P, Salizzoni M, Bruix J, Forner A, De Carlis L, Cillo U, Burroughs AK, Troisi R, Rossi M, Gerunda GE, Lerut J, Belghiti J, Boin I, Gugenheim J, Rochling F, Van Hoek B, Majno P: Predicting survival after liver transplantation in patients with hepatocellular carcinoma beyond the Milan criteria: a retrospective, exploratory analysis. Lancet Oncol 2009, 10(1):35-43.

2. Edwards $C Q$, Dadone $M M$, Skolnick $M H$, Kushner JP: Hereditary haemochromatosis. Clin Haematol 1982, 11(2):411-435.

3. Tavill AS: Diagnosis and management of hemochromatosis. Hepatology 2001, 33(5):1321-1328.

4. Niederau C, Fischer R, Sonnenberg A, Stremmel W, Trampisch HJ, Strohmeyer G: Survival and causes of death in cirrhotic and in noncirrhotic patients with primary hemochromatosis. N Engl J Med 1985, 313(20):1256-1262.

5. Fargion S, Mandelli C, Piperno A, Cesana B, Fracanzani AL, Fraquelli M, Bianchi PA, Fiorelli G, Conte D: Survival and prognostic factors in 212 Italian patients with genetic hemochromatosis. Hepatology 1992, 15(4):655-659.

6. Feder JN, Gnirke A, Thomas W, Tsuchihashi Z, Ruddy DA, Basava A, Dormishian F, Domingo R Jr, Ellis MC, Fullan A, Hinton LM, Jones NL, Kimmel BE, Kronmal GS, Lauer P, Lee VK, Loeb DB, Mapa FA, McClelland E, Meyer NC, Mintier GA, Moeller N, Moore T, Morikang E, Prass CE, Quintana L, Starnes SM, Schatzman RC, Brunke KJ, Drayna DT, Risch NJ, Bacon BR, Wolff RK: A novel MHC class I-like gene is mutated in patients with hereditary haemochromatosis. Nat Genet 1996, 13(4):399-408.

7. Shi WJ, Chen H, Zhou B, Cheng J: [Association of mutations of HFE gene and hepatocellular carcinoma following chronic hepatitis B]. Zhonghua Gan Zang Bing Za Zhi 2005, 13(9):682-684.

8. Lauret E, Rodriguez M, Gonzalez S, Linares A, Lopez-Vazquez A, MartinezBorra J, Rodrigo L, Lopez-Larrea C: HFE gene mutations in alcoholic and virus-related cirrhotic patients with hepatocellular carcinoma. Am J Gastroenterol 2002, 97(4):1016-1021.

9. Fargion S, Stazi MA, Fracanzani AL, Mattioli M, Sampietro M, Tavazzi D, Bertelli C, Patriarca V, Mariani C, Fiorelli G: Mutations in the HFE gene and their interaction with exogenous risk factors in hepatocellular carcinoma. Blood Cells Mol Dis 2001, 27(2):505-511.

10. Willis G, Bardsley V, Fellows IW, Lonsdale R, Wimperis JZ, Jennings BA: Hepatocellular carcinoma and the penetrance of HFE C282Y mutations: a cross sectional study. BMC Gastroenterol 2005, 5:17. 
11. Hellerbrand C, Poppl A, Hartmann A, Scholmerich J, Lock G: HFE C282Y heterozygosity in hepatocellular carcinoma: evidence for an increased prevalence. Clin Gastroenterol Hepatol 2003, 1(4):279-284

12. Cauza E, Peck-Radosavljevic M, Ulrich-Pur H, Datz C, Gschwantler M, Schoniger-Hekele M, Hackl F, Polli C, Rasoul-Rockenschaub S, Muller C, Wrba F, Gangl A, Ferenci P: Mutations of the HFE gene in patients with hepatocellular carcinoma. Am J Gastroenterol 2003, 98(2):442-447.

13. Willis G, Wimperis JZ, Lonsdale R, Fellows IW, Watson MA, Skipper LM, Jennings BA: Incidence of liver disease in people with HFE mutations. Gut 2000, 46(3):401-404.

14. Ezzikouri S, El Feydi AE, El Kihal L, Afifi R, Benazzouz M, Hassar M, Chafik A, Pineau P, Benjelloun S: Prevalence of common HFE and SERPINA1 mutations in patients with hepatocellular carcinoma in a Moroccan population. Arch Med Res 2008, 39(2):236-241.

15. Nahon $P$, Sutton $A$, Rufat $P$, Ziol M, Thabut $G$, Schischmanoff $P O$, Vidaud $D$, Charnaux N, Couvert P, Ganne-Carrie N, Trinchet JC, Gattegno L, Beaugrand M: Liver iron, HFE gene mutations, and hepatocellular carcinoma occurrence in patients with cirrhosis. Gastroenterology 2008, 134(1):102-110.

16. Ropero P, Briceno O, Lopez-Alonso G, Agundez JA, Gonzalez Fernandez FA, Garcia-Hoz F, Villegas Martinez A, Diaz-Rubio M, Ladero JM: [The H63D mutation in the HFE gene is related to the risk of hepatocellular carcinoma]. Rev Esp Enferm Dig 2007, 99(7):376-381.

17. Boige V, Castera L, de Roux N, Ganne-Carrie N, Ducot B, Pelletier G, Beaugrand $M$, Buffet $C$ : Lack of association between HFE gene mutations and hepatocellular carcinoma in patients with cirrhosis. Gut 2003, 52(8):1178-1181

18. Racchi O, Mangerini R, Rapezzi D, Gaetani GF, Nobile MT, Picciotto A, Ferraris AM: Mutations of the HFE gene and the risk of hepatocellular carcinoma. Blood Cells Mol Dis 1999, 25(5-6):350-353.

19. Campo S, Restuccia T, Villari D, Raffa G, Cucinotta D, Squadrito G, Pollicino T, Raimondo G: Analysis of haemochromatosis gene mutations in a population from the Mediterranean Basin. Liver 2001, 21(4):233-236.

20. Beutler E, Felitti VJ, Koziol JA, Ho NJ, Gelbart T: Penetrance of 845G-> A (C282Y) HFE hereditary haemochromatosis mutation in the USA. Lancet 2002, 359(9302):211-218

21. Constantine CC, Gurrin LC, MCLaren CE, Bahlo M, Anderson GJ, Vulpe CD, Forrest SM, Allen KJ, Gertig DM: SNP selection for genes of iron metabolism in a study of genetic modifiers of hemochromatosis. BMC Med Genet 2008, 9:18.

22. Lau J, loannidis JP, Schmid CH: Quantitative synthesis in systematic reviews. Ann Intern Med 1997, 127(9):820-826.

23. Zintzaras $E$, loannidis JP: Heterogeneity testing in meta-analysis of genome searches. Genet Epidemiol 2005, 28(2):123-137.

24. Higgins JP, Thompson SG: Quantifying heterogeneity in a meta-analysis. Stat Med 2002, 21(11):1539-1558.

25. Egger M, Davey Smith G, Schneider M, Minder C: Bias in meta-analysis detected by a simple, graphical test. BMJ 1997, 315(7109):629-634

26. Begg CB, Mazumdar M: Operating characteristics of a rank correlation test for publication bias. Biometrics 1994, 50(4):1088-1101.

27. Dupont WD, Plummer WD Jr: Power and sample size calculations for studies involving linear regression. Control Clin Trials 1998, 19(6):589-601.

28. Wacholder S, Chanock S, Garcia-Closas M, El Ghormli L, Rothman N: Assessing the probability that a positive report is false: an approach for molecular epidemiology studies. J Natl Cancer Inst 2004, 96(6):434-442.

29. Bruzzi P, Green SB, Byar DP, Brinton LA, Schairer C: Estimating the population attributable risk for multiple risk factors using case-control data. Am J Epidemiol 1985, 122(5):904-914.

30. Pirisi M, Toniutto P, Uzzau A, Fabris C, Avellini C, Scott C, Apollonio L, Beltrami CA, Bresadola F: Carriage of HFE mutations and outcome of surgical resection for hepatocellular carcinoma in cirrhotic patients. Cancer 2000, 89(2):297-302.

31. Beckman LE, Hagerstrand I, Stenling R, Van Landeghem GF, Beckman L: Interaction between haemochromatosis and transferrin receptor genes in hepatocellular carcinoma. Oncology 2000, 59(4):317-322

32. Feder JN, Penny DM, Irrinki A, Lee VK, Lebron JA, Watson N, Tsuchihashi Z, Sigal E, Bjorkman PJ, Schatzman RC: The hemochromatosis gene product complexes with the transferrin receptor and lowers its affinity for ligand binding. Proc Natl Acad Sci USA 1998, 95(4):1472-1477.
33. Niederau C, Fischer R, Purschel A, Stremmel W, Haussinger D, Strohmeyer G: Long-term survival in patients with hereditary hemochromatosis. Gastroenterology 1996, 110(4):1107-1119.

34. Haddow JE, Palomaki GE, McClain M, Craig W: Hereditary haemochromatosis and hepatocellular carcinoma in males: a strategy for estimating the potential for primary prevention. J Med Screen 2003, 10(1):11-13.

35. Asberg A, Hveem K, Thorstensen K, Ellekjter E, Kannelonning K, Fjosne U, Halvorsen TB, Smethurst HB, Sagen E, Bjerve KS: Screening for hemochromatosis: high prevalence and low morbidity in an unselected population of 65,238 persons. Scand J Gastroenterol 2001, 36(10):1108-1115.

36. Allen KJ, Gurrin LC, Constantine CC, Osborne NJ, Delatycki MB, Nicoll AJ, McLaren CE, Bahlo M, Nisselle AE, Vulpe CD, Anderson GJ, Southey MC, Giles GG, English DR, Hopper JL, Olynyk JK, Powell LW, Gertig DM: Ironoverload-related disease in HFE hereditary hemochromatosis. N Engl J Med 2008, 358(3):221-230.

37. Ellervik C, Birgens $H$, Tybjaerg-Hansen A, Nordestgaard BG: Hemochromatosis genotypes and risk of 31 disease endpoints: metaanalyses including 66,000 cases and 226,000 controls. Hepatology 2007, 46(4):1071-1080

38. Ganne-Carrie N, Christidis C, Chastang C, Ziol M, Chapel F, Imbert-Bismut F, Trinchet JC, Guettier C, Beaugrand M: Liver iron is predictive of death in alcoholic cirrhosis: a multivariate study of 229 consecutive patients with alcoholic and/or hepatitis C virus cirrhosis: a prospective follow up study. Gut 2000, 46(2):277-282.

doi:10.1186/1756-9966-29-18

Cite this article as: Jin et al.: Association between C282Y and H63D mutations of the HFE gene with hepatocellular carcinoma in European populations: a meta-analysis. Journal of Experimental \& Clinical Cancer Research 2010 29:18.

\section{Submit your next manuscript to BioMed Central and take full advantage of:}

- Convenient online submission

- Thorough peer review

- No space constraints or color figure charges

- Immediate publication on acceptance

- Inclusion in PubMed, CAS, Scopus and Google Scholar

- Research which is freely available for redistribution

Submit your manuscript at www.biomedcentral.com/submit
C Biomed Central 